"DIE GANZE JANITSCHARENMUSIK DER WELTQUAL« 


\section{Heine-Studien}

Herausgegeben von Joseph A. Kruse Heinrich-Heine-Institut der Landeshauptstadt Düsseldorf 
Maria-Christina Boerner

\title{
»Die ganze \\ Janitscharenmusik \\ der Weltqual«
}

\author{
Heines Auseinandersetzung \\ mit der romantischen Theorie
}

Verlag J. B. Metzler

Stuttgart - Weimar 


\section{Meiner Mutter und Bruno}

Die Deutsche Bibliothek - CIP-Einheitsaufnahme

Boerner, Maria-Christina:

"Die ganze Janitscharenmusik der Weltqual" :

Heines Auseinandersetzung mit der romantischen Theorie / Maria-Christina Boerner. - Stuttgart ; Weimar : Metzler, 1998

(Heine-Studien)

ISBN 978-3-476-01598-3

ISBN 978-3-476-01598-3

ISBN 978-3-476-03740-4 (eBook)

DOI 10.1007/978-3-476-03740-4

Dieses Werk einschließlich aller seiner Teile ist urheberrechtlich geschützt. Jede Verwertung außerhalb der engen Grenzen des Urheberrechtsgesetzes ist ohne Zustimmung des Verlages unzulässig und strafbar. Das gilt insbesondere für Vervielfältigungen, Übersetzungen, Mikroverfilmungen und die Einspeicherung und Verarbeitung in elektronischen Systemen.

(C) 1998 Springer-Verlag GmbH Deutschland

Ursprünglich erschienen bei J. B. Metzlersche Verlagsbuchhandlung und Carl Ernst Poeschel Verlag GmbH in Stuttgart 1998 
Inhaltsverzeichnis

Vorwort

Einleitung

I. Historische Voraussetzungen: Das "bürgerliche" Zeitalter.-Die Ambivalenz von technisch-industriellem Fortschritt und politischer Restauration

II. "Die wahren Zerrissenen sind die wahren Kreuzträger der Zeit."

2.1. Heine und der "Chor weltschmerzlicher Hänflinge" Melancholischer Weltschmerz, jungdeutsche Zerrissenheit und Heines Abgrenzungsversuche

2.2. Der "Milchbruder Lord Byrons" - Heines Zerrissenheit in der zeitgenössischen Rezeption und in der Forschung

III. Romantik und Moderne 93

3.1. Heine und sein romantischer "Schulmeister" August Wilhelm Schlegel 93

3.2. "Das Alte ist gestorben, und wer wahr ist, ist modern." Oder: die Rivalität der romantischen Kunsttheorie und der Hegelschen Ästhetik 114

3.3. Heine und der ästhetische "Doktrinär" Friedrich Schlegel_132

3.4. Lucinde und Seraphine - Überwindung der Zerrissenheit durch Liebe? 145

3.5. "O süße Torheit, verlaß mich nicht!" (B II, 422) - Heine, der romantische Narr?

IV. Spurensuche 169

4.1. Vorbilder oder: "Die Literaturgeschichte ist die große Morgue wo jeder seine Toten aufsucht, die er liebt oder womit er verwandt ist." (B III, 372-373) 169

4.2. Cervantes-Lektüre - Mit Don Quixote im Kampf gegen Ludwig Börne 198

4.3. Romantische Lesefrüchte: Roman, Witz und Kontrastästhetik 230

4.4. "Der beste der Humoristen!" - Heine und Jean Paul 257 
4.5. Der "Meister der Ironie" in der Auseinandersetzung mit der romantischen Ironie 268

4.7. Die Ambivalenz des Schönen und des Häßlichen und die Diskussion um die Wahrheit in der Kunst 322

V. Schluß: Heine - ein moderner Dichter? 356

Literaturverzeichnis 371

I. Primärliteratur 371

1. Heine-Ausgaben 371

2. Quellen und Materialsammlungen zu Heine 371

3. Sonstige Texte und Anthologien 372

II. Sekundärliteratur 375

1. Sammelbände und Handbücher 375

2. Monographien und Aufsätze 377

Namensregister 391 


\section{Vorwort}

Die vorliegende Arbeit wurde im Sommersemester 1996 der Philosophischen Fakultät der Freien Universität Berlin unter dem Titel "Die ganze Janitscharenmusik der Weltqual" Heines Selbstverständnis als Prosa-Dichter und die Auseinandersetzung mit der romantischen Theorie um die Paradigmen der modernen Literatur als Dissertation eingereicht. An dieser Stelle möchte ich noch einmal all denen herzlich danken, die zum Gelingen dieser Arbeit beigetragen haben. In erster Linie danke ich hierfür meinem Doktorvater Prof. Dr. Günter Holtz (Berlin), der mir immer mit Rat und Tat zur Seite stand.

Mein besonderer Dank gilt Herrn Prof. Dr. Stefan Bodo Würffel (Fribourg), der immer ein offenes Ohr für Fragen zu Heine hat und mich bei bei der Drucklegung der Dissertation unterstützte.

Schließlich möchte ich auch Prof. Dr. Joseph A. Kruse (Düsseldorf) für die Bereitschaft danken, diese Arbeit in die Reihe der Heine-Studien aufzunehmen, sowie der Studienstiftung für das zweijährige Stipendium, das mir ein ungestörtes Forschen ermöglichte.

Gewidmet ist diese Arbeit den beiden Menschen, die sie mir vermöge ihrer Liebe, Geduld und jeweder Form der Unterstützung erst ermöglicht haben: meiner Mutter und meinem Mann Bruno. 